\title{
Comment on "Failure of the Pipeline Embolization Device in Posterior Communicating Artery Aneurysms Associated with a Fetal Posterior Cerebral Artery"
}

\author{
Visish M. Srinivasan and Peter Kan \\ Department of Neurosurgery, Baylor College of Medicine, Houston, TX, USA \\ Correspondence should be addressed to Peter Kan; peter.kan@bcm.edu \\ Received 18 May 2016; Accepted 10 January 2017; Published 15 March 2017 \\ Academic Editor: Boris Krischek \\ Copyright ( 2017 Visish M. Srinivasan and Peter Kan. This is an open access article distributed under the Creative Commons \\ Attribution License, which permits unrestricted use, distribution, and reproduction in any medium, provided the original work is \\ properly cited.
}

We read with interest the article by Zanaty et al. "Failure of the Pipeline Embolization Device in Posterior Communicating Artery Aneurysms Associated with a Fetal Posterior Cerebral Artery" [1].

The authors presented a case series of 4 patients who had been treated with the pipeline embolization device for posterior communicating artery (PCoA) aneurysms across several institutions. However, their review of the previously published literature is incomplete and indeed this phenomenon has been described by our own series of 4 patients several months earlier [2]. Soon, thereafter, it was described by Tsang et al. [3], and followed by the recent article by Zanaty et al. These publications were likely in development simultaneously, but we wish to point out the previously published literature on the topic and reinforce the phenomenon observed across the 3 series.

All 12 cases ( 4 in each series) involved posterior communicating artery aneurysms that incorporated a fetal origin of the posterior cerebral artery (PCA). The large flow demand of the fetal PCA causes flow across the aneurysm and into the distal PCA territory, preventing successful flow diversion. Without diversion of flow, the aneurysm remains patent and treatment fails. The same concept applies to other aneurysms incorporating "end vessels"; we recently presented this concept at the AANS 2016 meeting [4] and subsequently published it in Journal of Neurosurgery [5].

\section{Competing Interests}

Visish M. Srinivasan declares no conflict of interests. Peter Kan is a consultant for Medtronic and Stryker Neurovascular.

\section{References}

[1] M. Zanaty, N. Chalouhi, R. M. Starke et al., "Failure of the pipeline embolization device in posterior communicating artery aneurysms associated with a fetal posterior cerebral artery," Case Reports in Vascular Medicine, vol. 2016, Article ID 4691275, 4 pages, 2016.

[2] P. Kan, E. Duckworth, A. Puri, G. Velat, and A. Wakhloo, "Treatment failure of fetal posterior communicating artery aneurysms with the pipeline embolization device," Journal of NeuroInterventional Surgery, vol. 8, no. 9, pp. 945-948, 2016.

[3] A. C. Tsang, A. M. Fung, F. C. Tsang, G. K. Leung, R. Lee, and W. M. Lui, "Failure of flow diverter treatment of intracranial aneurysms related to the fetal-type posterior communicating artery," Neurointervention, vol. 10, no. 2, pp. 60-66, 2015.

[4] V. Srinivasan, P. Kan, N. Mbabuike et al., "Oral presentations 2016 AANS Annual Scientific Meeting Chicago, IL - April 30-May 4, 2016 published online April 1, 2016; DOI: 10.3171/2016.4.JNS.AANS2016abstracts," Journal of Neurosurgery, vol. 124, pp. A1146-A1209, 2016.

[5] P. Kan, V. M. Srinivasan, N. Mbabuike et al., "Aneurysms with persistent patency after treatment with the Pipeline Embolization Device," Journal of Neurosurgery, 2016. 


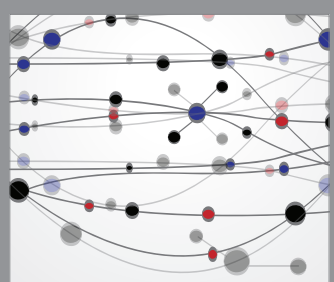

The Scientific World Journal
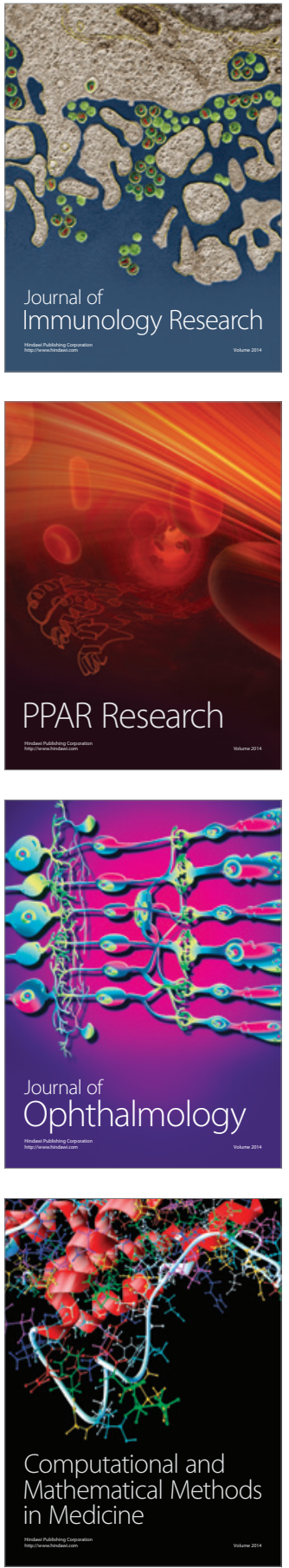

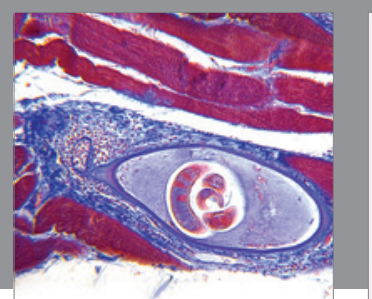

Gastroenterology Research and Practice
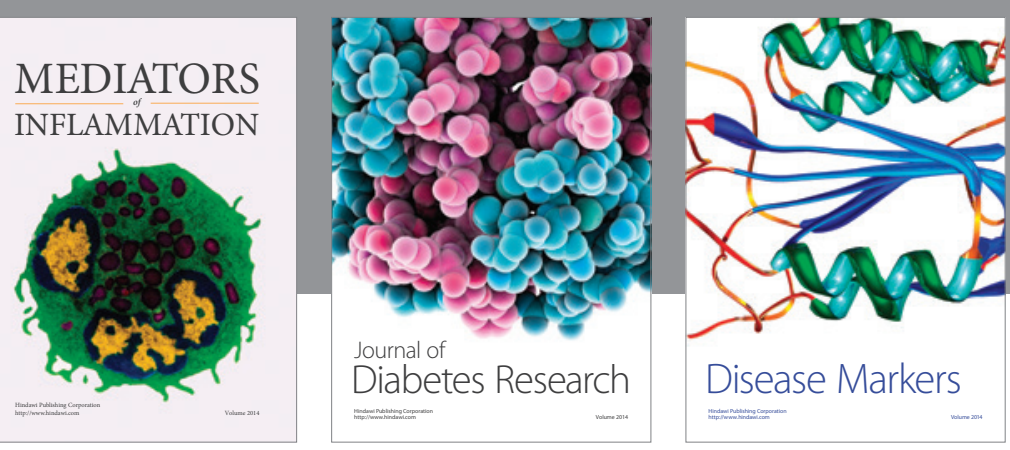

Disease Markers

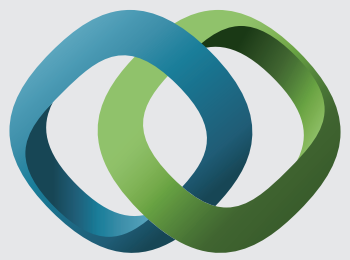

\section{Hindawi}

Submit your manuscripts at

https://www.hindawi.com
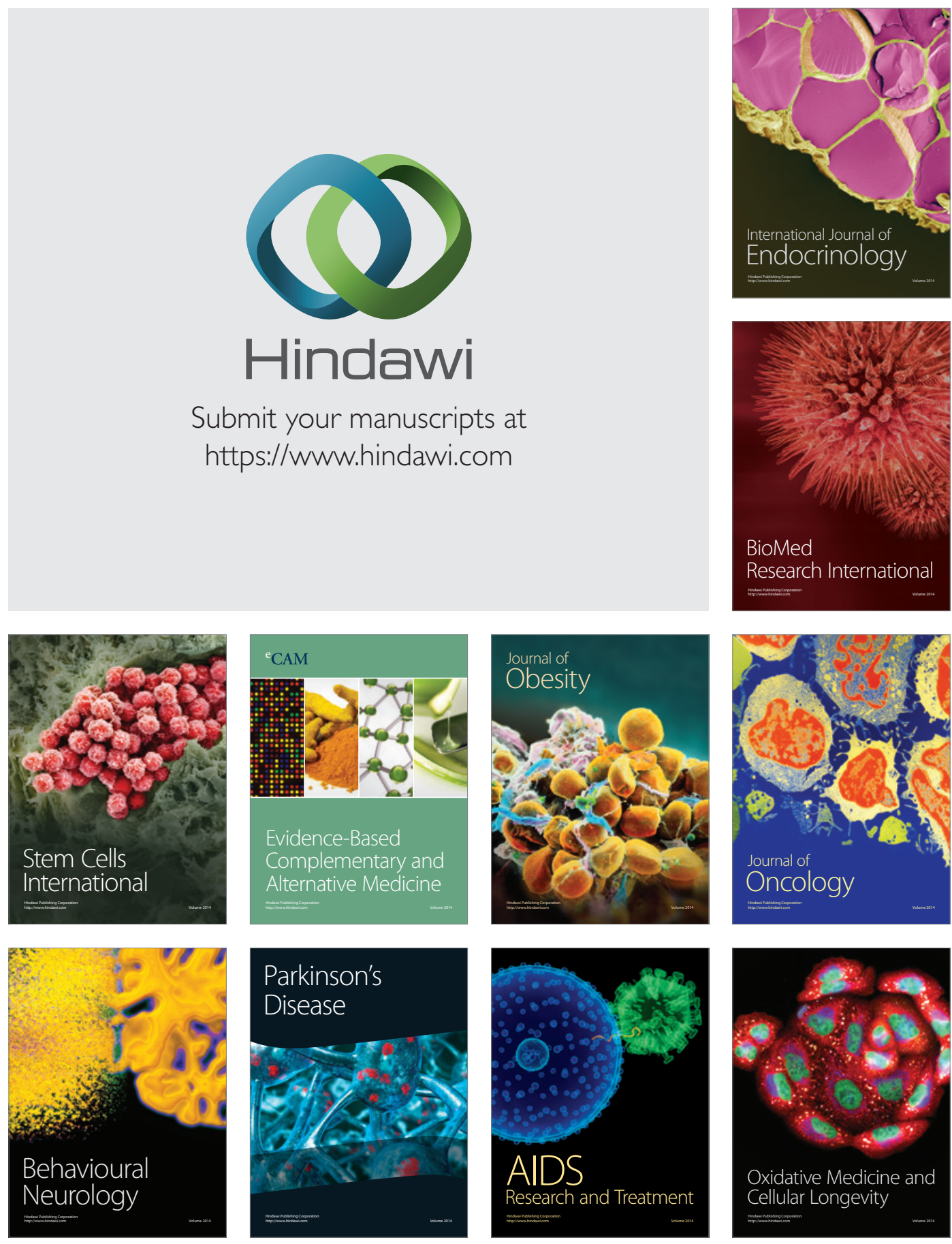